\title{
Evaluasi Numerik untuk Delaminasi Komposit Double Cantilever Beam dengan Cohesive Zone Model
}

\author{
Nuri Setyo Taufiqqurrahman, Mas Irfan P. Hidayat, dan Amaliya Rasyida \\ Jurusan Teknik Material dan Metalurgi, Fakultas Teknologi Industri, Institut Teknologi Sepuluh Nopember (ITS) \\ Jl. Arief Rahman Hakim, Surabaya 60111 Indonesia \\ e-mail: irfan@mat-eng.its.ac.id
}

\begin{abstract}
Abstrak-Material komposit saat ini terus berkembang, salah satunya adalah material komposit laminat. Material komposit laminat terdiri dari lamina-lamina dimana ikatan yang berdekatan kerap terdeformasi, yang biasa disebut sebagai delaminasi. Delaminasi pada material komposit laminat dapat dianalisis menggunakan metode numerik dimana dalam penelitian ini menggunakan software yang berbasis elemen hingga, yaitu ANSYS Mechanical/APDL. Untuk mengetahui proses delaminasi yang terjadi, double cantilever beam di modelkan dengan pemberian beban berupa displacement. Variasi penelitain yang digunakan diantaranya arah serat, letak initial crack, dan panjang initial crack. Dari hasil simulasi didapatkan bahwa, double cantilever beam dengan panjang initial crack 30 $\mathrm{mm}$ dan arah serat $0^{\circ}$ memiliki reaction force yang paling tinggi, yaitu 116.68 N pada ketebalan beam yang sama. Double cantilever beam dengan panjang initial crack $55 \mathrm{~mm}$ dan arah serat $90^{\circ}$ membutuhkan reaction force yang paling kecil diantaranya, yaitu 22.9 N. Double cantilever beam yang dibeberapa kasus memiliki tebal yang berbeda memberikan hasil yang menunjukkan bahwa semakin tebal beam maka reaction force yang dibutuhkan semakin besar.
\end{abstract}

Kata Kunci-Cohesive Zone Model, Delaminasi, Double Cantilever Beam, Komposit Laminat

\section{PENDAHULUAN}

$\mathrm{D}$ EWASA ini, material komposit sering digunakan untuk mengganti material-material konvensional. Hal ini dilakukan karena material komposit memiliki sifat material yang lebih unggul daripada material-material konvensional. Penggunaan material komposit ini sendiri sebenarnya sudah dimulai sejak ribuan tahun yang lalu, bahkan sebelum Masehi. Puncak penggunaan material komposit sendiri bermula pada akhir abad 20 dimana penggunaan material komposit banyak menggantikan material-material konvensional hingga sekarang [1].

Di dunia teknik, penggunaan material komposit sangat dominan dibidang aerospasial dan otomotif, seperti mobil dan alat transportasi lain. Hal ini dikarenakan material komposit memiliki sifat kombinasi yang diinginkan di beberapa hal seperti perancangan struktur, biaya manufaktur, dan ketahanan fatik yang tida.k didapatkan dari material konvensional [2].

Dominannya penggunaan material komposit menuntut industri manufaktur agar mampu memprediksikan kekuatan dan ketahanan material komposit dengan baik. Karena kegagalan pada material komposit dapat menyebabkan hal yang fatal. Salah satu kegagalan yang sering terjadi pada material komposit adalah pengelupasan antar lamina atau delaminasi [3]. Simulasi mengenai delaminasi yang terjadi material komposit dengan tiga variabel yang berbeda ini (arah serat, panjang initial crack, dan letak initial crack), diharapkan simulasi ini dapat digunakan untuk memprediksikan proses delaminasi yang terjadi pada material komposit laminat dengan menggunakan metode cohesive zone model pada simulasi menggunakan software yang berbasis elemen hingga, ANSYS Mechanical/APDL.

Cohesive $z$ one model adalah teknik batasan kerja dari continuum damage mechanics yang dapat memprediksikan inisiasi dan perambatan delaminasi pada material komposit. [4]. Menurut Camanho [5], terdapat beberapa beberapa kelebihan dari metode ini, yaitu:

1. Mampu memprediksikan inisiasi dan pertumbuhan delaminasi tanpa membuat asumsi retak sebelumnya.

2. Dapat diaplikasikan pada struktur yang kompleks yang ditujukan untuk pembebanan yang kompleks.

Cohesive zone model menghubungkan traction dengan displacement pada interface dimana retakan atau crack dapat berkembang. Sifat dari cohesive zone model ini dinyatakan oleh Gambar 1. Kurva bilinear tersebut mempunyai sifat seperti berikut:

1. Area elastis awal memiliki sifat kekakuan (stiffness) yang tinggi hingga tegangan mencapai interface strength $\left(\sigma_{\max }\right)$.

2. Berikutnya diikuti dengan area pelunakan (softening) hingga tegangan mencapai nol.

3. Area dibawah kurva sama dengan interlaminar fracture toughness $\left(\mathrm{G}_{\mathrm{IC}}\right)$

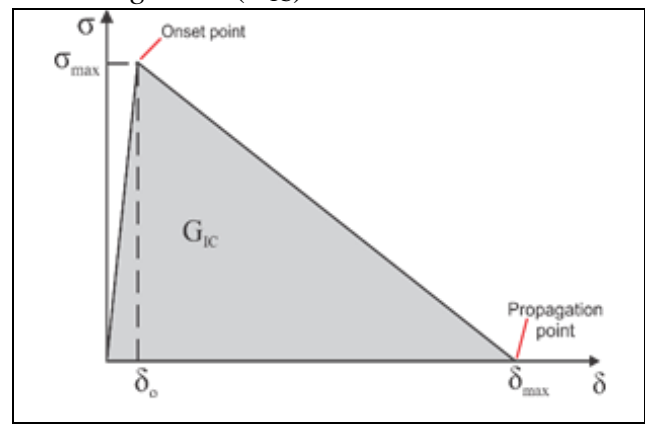

Gambar 1. Bilinear constitutive equation cohesive element [4] 
M. Meo dan E. Thieulot (2005) melakukan penelitian menggunakan metode cohesive zone model (CZM), virtual crack closure technique (VCCT), dan tiebreak contact. Pada penelitian dengan teknik pertama dan kedua, cohesive zone model dengan perbedaan pada interface, memberikan hasil yang positif dimana kurva load-displacement menunjukkan tren yang sama. Sedangkan untuk teknik yang ketiga, VCCT, yang menggunakan energy release rate sebagai acuan menunjukkan tren yang tidak jauh berbeda dengan teknik pertama, CZM. Tren yang berbeda ditunjukkan oleh teknik keempat, tiebreak contact. Teknik ini tidak mampu memprediksikan proses pertumbuhan delaminasi dengan akurat. Alasan utama mengapa hal ini dapat terjadi adalah karena kriteria kegagalan yang ditetapkan berdasarkan pada tegangan maksimal interlaminar dan bukan pada energy release rate kritis walaupun terdapat pertumbuhan delaminasi sebelum energy release rate kritis tercapai [6].

Reis dkk. (2009) meneliti mengenai pengaruh panjang dari initial crack pada fracture toughness mode I dengan double cantilever beam test. Kegagalan delaminasi juga diprediksikan menggunakan metode simulasi dengan exponential cohesive model. Dari penelitiannya, Reis dkk. menyimpulkan bahwa double cantilever beam yang dimodelkan menggunakan interface element dengan metode energi kohesif sesuai dengan kurva load-displacement yang didapatkan secara numerikal dan eksperimental. Sensitivitas relatif cukup baik terhadap parameter numerik ( $\mathrm{G}_{\mathrm{IC}}$ dan vc). Initial crack yang semakin panjang akan menghasilkan rigidity yang lebih kecil dan tidak mempengaruhi damage progression [7].

Pada tahun 2014, Giuliese dkk. melakukan penelitian numerikal mengenai delaminasi menggunakan teknik cohesive zone model. Sebelumnya, Giulese dkk. telah terlebih dahulu meneliti masalah delaminasi pada beam dua dimensi. Dengan bekal penelitian sebelumnya tersebut, Giulese dkk. mengembangkan konsep ini lebih lanjut menjadi tiga dimensi. Double cantilever beam dengan Mode I dijadikan sebagai geometri penelitian. Properties dari material komposit yang digunakan telah ditentukan. Begitu pula dengan dimensi dari double cantilever beam. Hasilnya, penelitian yang dilakukan sesuai dengan teori yang ada [8].

Pada tahun 2014, Wassem dan Kumar melakukan penelitian menggunakan dua metode, yaitu VCCT dan CZM. Penelitian dilakukan dengan menggunakan software ANSYS Workbench dengan model dua dimensi. Keduanya memberikan hasil simulasi yang baik. Akan tetapi, VCCT menaksir critical load yang terlalu tinggi; sedangkan CZM menampilkan hasil yang memuaskan karena hasil dari pemodelan menunjukkan keserasian dengan hasil eksperimen untuk metode kontak dan interface. Selain itu, Waseem juga menyimpulkan bahwa dengan bertambahnya ketebalan double cantilever beam, maka gaya yang dibutuhkan untuk mendeformasikan cohesive zone akan semakin meningkat seperti pada Gambar 2. Double cantilever beam dengan ketebalan $3 \mathrm{~mm}$ membutuhkan force yang paling besar dibandingkan dengan double cantilever beam dengan tebal $2 \mathrm{~mm}, 1.5 \mathrm{~mm}, 1.2 \mathrm{~mm}$, dan $1 \mathrm{~mm}$ [9].

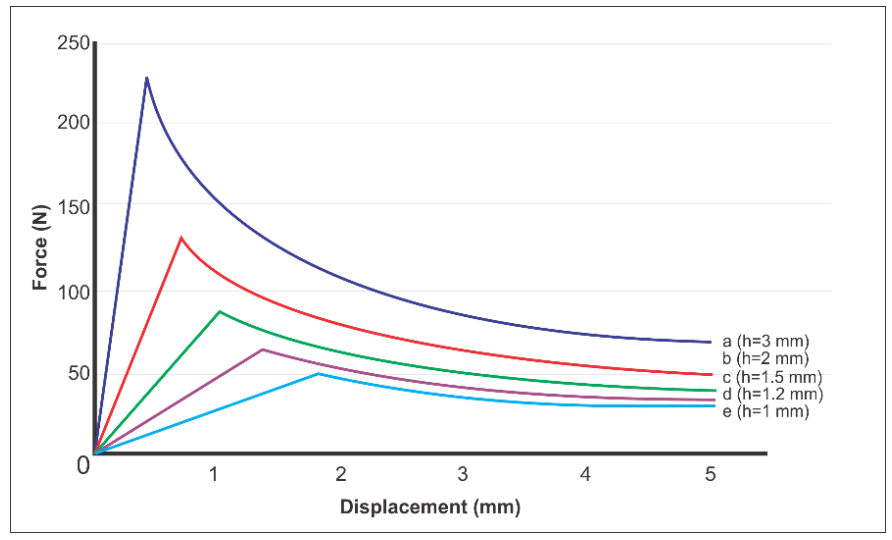

Gambar 2. Kurva reaction force-displacement dengan ketebalan beam yang berbeda [9]

Penelitian ini mengkombinasikan beberapa variabel, spesimen, dan metode dari penelitian-penelitian sebelumnya mengenai delaminasi. Material komposit yang diteliti adalah material komposit double cantilever beam dengan serat karbon dan matriks epoksi. Penelitian numerik ini menggunakan software yang berbasis metode elemen hingga, ANSYS Mechanical/APDL, dengan variabel arah serat karbon, panjang initial crack, dan letak initial crack.

\section{METODE PENELITIAN}

\section{A. Spesifikasi Material}

Pada penelitian ini, digunakan material komposit berpenguat karbon dengan matriks epoksi. Tabel 1 menunjukkan material properties dari double cantilever beam dan Tabel 2 menunjukkan material properties dari cohesive zone model. Sifat dari material yang digunakan dalam penelitian diambil dari penelitian Camanho [5] yang telah dilakukan olehnya pada tahun 2002.

Tabel 1.

Sifat mekanik dari material komposit [5]

\begin{tabular}{cccc}
\hline Sifat Mekanik & & Nilai & Unit \\
\hline \multirow{3}{*}{ Modulus Elasticity $(\mathrm{E})$} & $\mathrm{E}_{11}$ & 150 & \\
& $\mathrm{E}_{22}$ & 11 & $\mathrm{GPa}$ \\
& $\mathrm{E}_{33}$ & 11 & \\
& $\mathrm{v}_{12}$ & 0.25 & \\
Poisson's Ratio $(\mathrm{v})$ & $\mathrm{v}_{13}$ & 0.45 & - \\
& $\mathrm{v}_{23}$ & 0.25 & \\
\multirow{4}{*}{ Shear Modulus $(\mathrm{G})$} & $\mathrm{G}_{12}$ & 6 & $\mathrm{GPa}$ \\
& $\mathrm{G}_{13}$ & 3.7 & \\
\hline \hline
\end{tabular}

Tabel 2 .

Sifat mekanik dari cohesive zone [5]

\begin{tabular}{lcc}
\hline \multicolumn{1}{c}{ Sifat Mekanik } & Nilai & Unit \\
\hline Maximum normal stress $\left(\sigma_{\max }\right)$ & 45 & $\mathrm{MPa}$ \\
Fracture toughness Mode $\mathrm{I}\left(\mathrm{G}_{\mathrm{IC}}\right)$ & 0.268 & $\mathrm{~kJ} / \mathrm{m}^{2}$ \\
Stiffness penalty $(\mathrm{K})$ & $10^{6}$ & $\mathrm{~N} / \mathrm{mm}$ \\
\hline \hline
\end{tabular}

\section{B. Parameter}

Terdapat tiga parameter yang digunakan pada penelitian ini, yaitu arah serat, letak initial crack $\left(\mathrm{a}_{0}\right)$, dan panjang initial 
crack $\left(\mathrm{a}_{0}\right)$. Parameter ini dapat dilihat di Tabel 3. Dari parameter-parameter ini kemudian dibuat variasi penelitian seperti yang terlihat pada Tabel 4.

Tabel 3.

\begin{tabular}{cccc}
\multicolumn{4}{c}{ Parameter penelitian } \\
\hline \hline Parameter & Arah Serat & $\begin{array}{c}\text { Letak Initial crack } \\
\left(\mathrm{a}_{0}\right)\end{array}$ & $\begin{array}{c}\text { Panjang Initial } \\
\text { crack }\left(\mathrm{a}_{0}\right)\end{array}$ \\
\hline Kode & AS & MID/BOT & $55 / 45 / 30$ \\
Variasi 1 & $0^{\circ}$ & Tengah & $55 \mathrm{~mm}$ \\
Variasi 2 & $90^{\circ}$ & Bawah & $45 \mathrm{~mm}$ \\
Variasi 3 & - & - & $30 \mathrm{~mm}$ \\
\hline \hline
\end{tabular}

Tabel 4.

Variasi penelitian

\begin{tabular}{ccccc}
\hline \hline Kasus & $\begin{array}{c}\text { Arah } \\
\text { Serat }\end{array}$ & $\begin{array}{c}\text { Panjang } \\
\text { Initial crack }\end{array}$ & $\begin{array}{c}\text { Letak Initial } \\
\text { crack }\end{array}$ & Kode \\
\hline 1 & $0^{\circ}$ & 55 & Tengah & AS00-55-MID \\
2 & $90^{\circ}$ & 55 & Tengah & AS90-55-MID \\
3 & $0^{\circ}$ & 55 & Bawah & AS00-55-BOT \\
4 & $90^{\circ}$ & 55 & Bawah & AS90-55-BOT \\
5 & $0^{\circ}$ & 45 & Tengah & AS00-45-MID \\
6 & $90^{\circ}$ & 45 & Tengah & AS90-45-MID \\
7 & $0^{\circ}$ & 45 & Bawah & AS00-45-BOT \\
8 & $90^{\circ}$ & 45 & Bawah & AS90-45-BOT \\
9 & $0^{\circ}$ & 30 & Tengah & AS00-30-MID \\
10 & $90^{\circ}$ & 30 & Tengah & AS90-30-MID \\
11 & $0^{\circ}$ & 30 & Bawah & AS00-30-BOT \\
12 & $90^{\circ}$ & 30 & Bawah & AS90-30-BOT \\
\hline \hline
\end{tabular}

\section{Pemodelan}

Penelitian ini menggunakan double cantilever beam dengan dimensi seperti yang terlihat pada Gambar 3. Kemudian double cantilever beam ini disimulasikan dengan software yang berbasis elemen hingga, yaitu ANSYS Mechanical/APDL.

Double cantilever beam kemudian diberikan beban berupa displacement di salah satu ujung dan ujung lainnya dijepit ke segala arah, seperti yang terlihat pada Gambar 4.

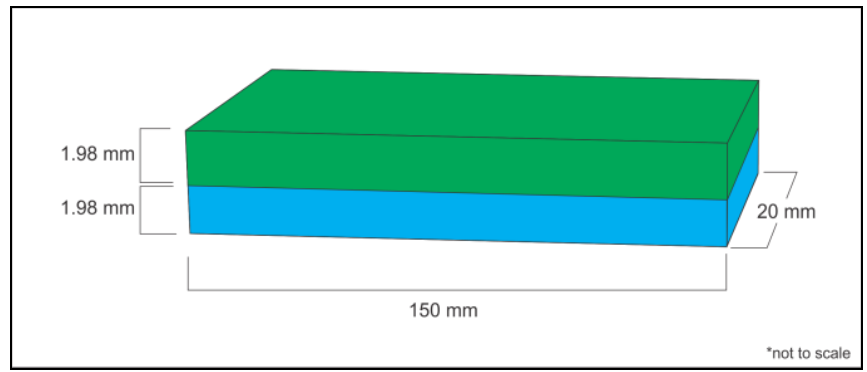

Gambar 3. Sketsa double cantilever beam

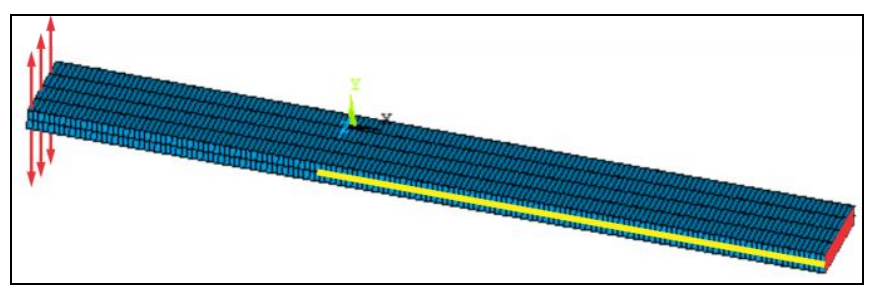

Gambar 4. Double cantilever beam yang telah dimodelkan pada ANSYS Mechanical/APDL dan diberikan displacement

\section{HASIL DAN PEMBAHASAN}

Proses delaminasi pada double cantilever beam yang telah diberikan beban berupa displacement dapat dilihat pada Gambar 5.

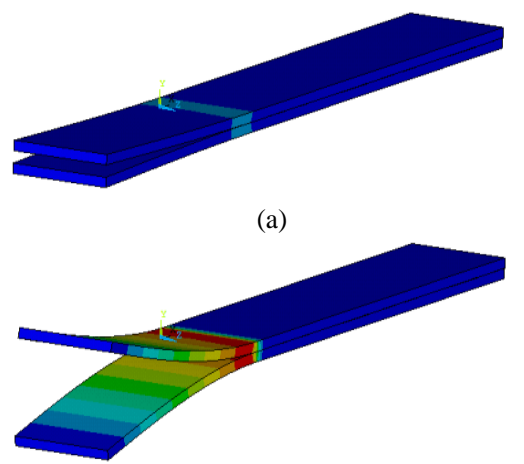

(b)

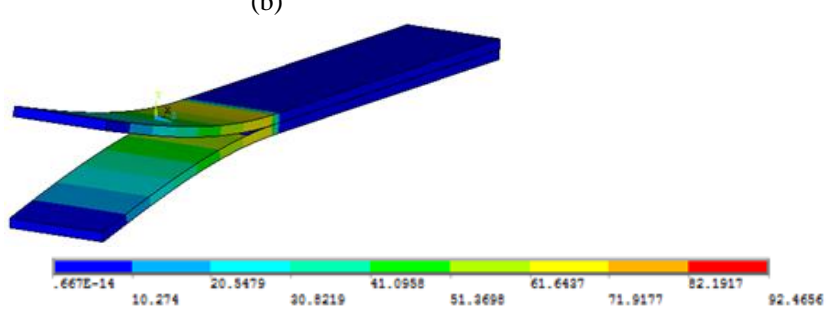

(c)

Gambar 5. Proses delaminasi saat (a) awal pembebanan (b) tegangan maksimum (c) setelah tegangan maksimum

Tegangan maksimum tercapai saat reaction force (gaya yang dibutuhkan untuk merusak cohesive zone) maksimum dengan nilai displacement yang berbeda pada setiap variasi penelitian.

\section{A. Pengaruh Arah Serat}

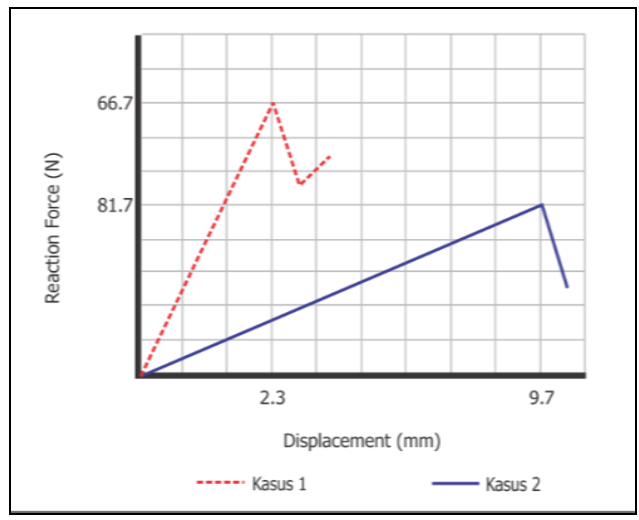

Gambar 6. Kurva hasil pembebanan untuk arah serat yang berbeda pada kasus 1 dan 2

Dari Gambar 6 terlihat bahwa arah serat yang berbeda membutuhkan reaction force yang berbeda. Kasus dengan nomor urutan ganjil (kasus 1,3,5,7,9, dan 11) memiliki konfigurasi arah serat $0^{\circ}$. Hasilnya, reaction force yang dibutuhkan lebih besar daripada kasus dengan nomor urutan genap (kasus 2,4,6,8,10, dan 12) yang memiliki konfigurasi arah serat $90^{\circ}$. Hal ini sesuai dengan teori bahwa kekuatan material komposit bernilai besar pada arah fiber dan bernilai kecil ada arah melintang [1], [10]. 


\section{B. Pengaruh Panjang Initial Crack}

Terdapat tiga variasi panjang initial crack pada penelitian ini, yaitu $55 \mathrm{~mm}, 45 \mathrm{~mm}$, dan $30 \mathrm{~mm}$. Hasil pada tiap variasi dapat dilihat pada Tabel 5. Selain itu, Gambar 5 juga memberikan informasi mengenai perbedaan nilai reaction force dan displacement.

Pada Gambar 7 terlihat bahwa semakin kecil initial crack maka semakin besar reaction force yang dibutuhkan untuk merusak cohesive zone. Kasus 1 memiliki panjang initial crack $30 \mathrm{~mm}$ dengan reaction force sebesar $116.68 \mathrm{~N}$, kasus 545 $\mathrm{mm}$ dengan reaction force $81.7 \mathrm{~N}$, dan kasus $955 \mathrm{~mm}$ dengan reaction force $66.7 \mathrm{~N}$. Hal ini sesuai dengan teori yang ada [11], [7].

Gambar 8 menunjukkan bahwa letak dari initial crack mempengaruhi reaction force yang dibutuhkan untuk merusak cohesive zone. Letak initial crack yang berada ditengah-tengah (seperti Gambar 3) memiliki nilai reaction force yang berbeda dengan initial crack yang berada di bagian bawah (seperti Gambar 9). Semakin tebal beam, maka semakin besar nilai reaction force. Kato dalam penelitiannya menyimpulkan bahwa semakin tipis coating maka proses delaminasi akan semakin mudah terjadi [12]. Hal ini sesuai dengan hasil penelitian yang telah dilakukan. Beam dengan ketebalan $2.64 \mathrm{~mm}$ membutuhkan reaction force lebih besar daripada beam dengan ketebalan $1.98 \mathrm{~mm}$ dan $1.32 \mathrm{~mm}$.

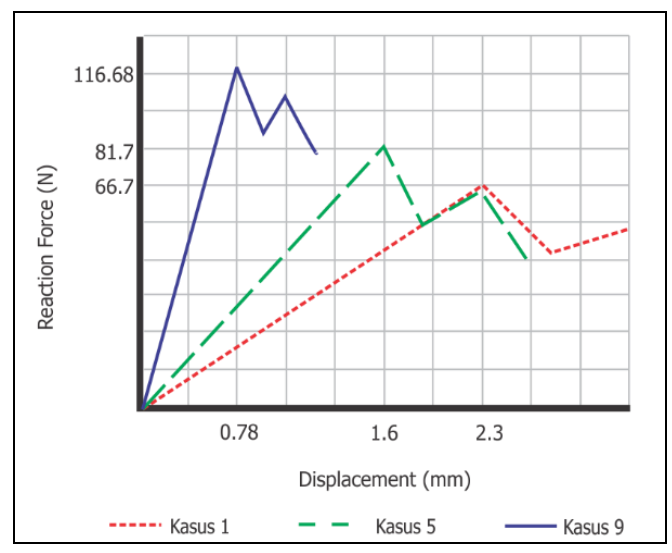

Gambar 7. Kurva hasil pembebanan untuk panjang initial crack yang berbeda pada kasus 1, 2, dan 9

\section{Pengaruh Letak Initial Crack}

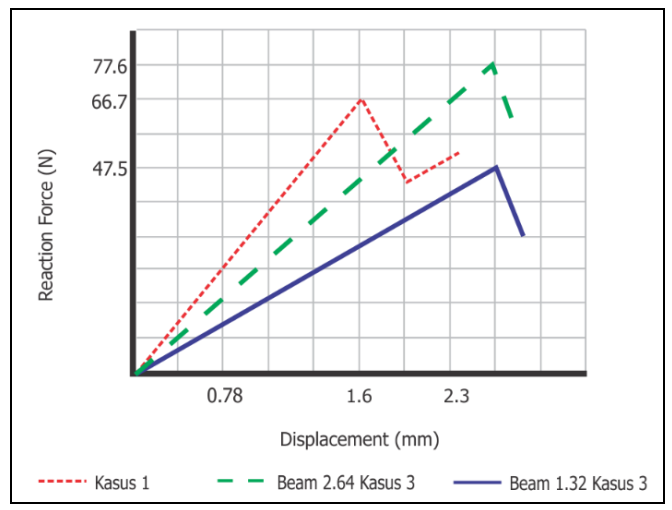

Gambar 8. Kurva hasil pembebanan untuk letak initial crack yang berbeda pada kasus 1 dan 3

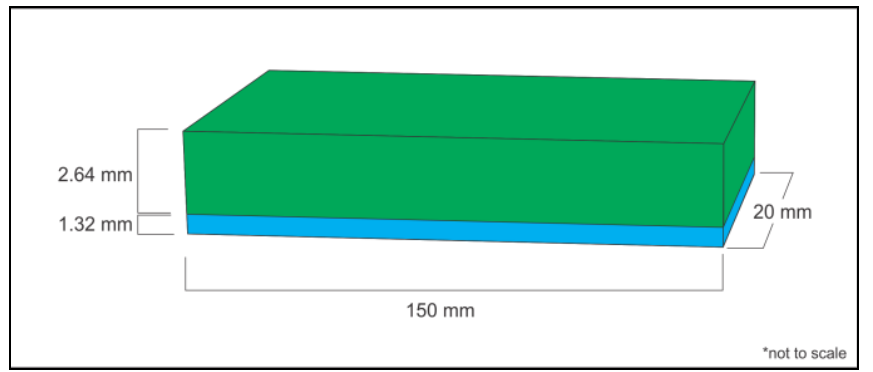

Gambar 9. Double cantilever beam dengan ketebalan yang berbeda

Dari hasil ini diketahui bahwa susunan material komposit harus disesuaikan dengan kebutuhan sifat material yang diinginkan, misalnya komponen sayap terbang. Samsu dan Pramono (2012) menyatakan bahwa komponen sayap pesawat terbang hendaknya memiliki tegangan maksimum yang tinggi. Dalam penelitiannya, perbedaan arah serat memberikan efek yang cukup signifikan. Sayap pesawat dengan arah serat $0^{\circ}$ mampu menahan tegangan lebih tinggi $87.9 \%$ dibandingkan dengan arah serat $90^{\circ}$. Oleh karena itu, jika material komposit diaplikasikan sebagai material sayap pesawat, maka arah serat dengan orientasi $0^{\circ}$ akan memberikan kekuatan yang lebih baik dibandingkan dengan material komposit dengan orientasi arah serat $90^{\circ}$ [13]

Nilai displacement untuk semua kasus dengan arah serat $0^{\circ}$ lebih rendah dibandingkan dengan kasus dengan arah serat $90^{\circ}$. Munasir (2011) dalam penelitian eksperimentalnya juga mendapati hasil yang sama. Material komposit yang hanya memiliki arah serat longitudinal memiliki nilai elongasi yang lebih rendah daripada material komposit dengan dua arah serat yang berbeda. Sehingga untuk mendapatkan material komposit dengan elongasi yang lebih baik dan nilai kekuatan yang baik maka dapat digunakan kombinasi laminat dengan perpaduan dua arah yang berbeda [14].

\section{KESIMPULAN}

Dari hasil penelitian dapat disimpulkan bahwa arah serat berpengaruh terhadap sifat material komposit. Nilai reaction force dari material komposit dengan arah serat $0^{\circ}$ lebih besar rata-rata $66 \%$ dibandingkan dengan nilai reaction force dengan arah serat $90^{\circ}$. Posisi initial crack juga memberikan pengaruh terhadap reaction force. Hal ini berkaitan dengan ketebalan beam. Beam yang memiliki tebal $2.64 \mathrm{~mm}$ rata-rata membutuhkan reaction force 30\% lebih besar dibandingkan dengan beam dengan ketebalan $1.32 \mathrm{~mm}$. Selain itu, panjang initial crack memiliki andil yang cukup besar dalam proses delaminasi. Initial crack yang memiliki panjang $30 \mathrm{~mm}$ cenderung membutuhkan reaction force $31 \%$ lebih besar jika dibandingkan dengan initial crack dengan panjang $45 \mathrm{~mm}$ dan $42 \%$ dengan $55 \mathrm{~mm}$.

\section{UCAPAN TERIMA KASIH}

Terima kasih yang sebesar-besarnya kepada semua pihak yang telah membantu penulis dalam menyelesaikan penelitian ini, terutama kepada keluarga tercinta yang telah memberikan 
dukungan moril dan materil yang tiada henti.

\section{DAFTAR PUSTAKA}

[1] Sulistijono. 2012. Mekanika Material Komposit. ITS Press: Surabaya.

[2] Campbell, F.C. 2010. Structural Composite Materials. ASM International. United States.

[3] Garg, Amar. 1988. Delamination-A Damage Mode in Composite Structures. Aeronautical Engineering Department, Indian Institute of Technology, Bombay-400 076, India.

[4] Seedifar, Milad, dkk. 2015. Prediction of Delamination Growth in Laminated Composites Using Acoustic Emission and Cohesive Zone modeling Techniques. Elsevier: 120-127.

[5] Camanho, P. Pedro, Davila. 2002. Mixed-Mode Decohesion Finite Elements for the Simulation of Delamination in Composite Materials. NASA/TM-2002-211737.

[6] Meo, M., dan E. Thieulot. 2005. Delamination Modelling In A Double cantilever beam. Elsevier: 29-43.

[7] Reis, dkk. 2009. Analysis Of The Initial Delamination Size On The Mode I Interlaminar Fracture Of Carbon/Epoxy Composites. Journal of Composite Materials, Vol. 43, page: 2609-2621.

[8] Giuliese, G., A. Pirondi, dan F. Moroni. 2014. A Cohesive Zone model for Three-dimensional Fatigue Debonding/ Delamination. Procedia Materials Science 3: 1473 - 1478.

[9] Wasseem, Mohammed, dan Kirain Kumar. 2014. Finite Element Modelling for Delamination Analysis of Double cantilever beam Specimen. SSRG-IJME. India.

[10] Callister, William. 2010. Materials Science and Engineering. John Wiley and Sons, Inc. United States of America. Page: 660.

[11] Anderson, Ted. 2005. Fracture Mechanics: Fundamental and Applications. Taylor and Francis. Boca Raton. Hal: 25-31.

[12] Kato, Masahiko, dkk. 2013. Effects of coating thickness and interfacial roughness on cracking and delamination strength of WC-Co coating measured by ring compression Test. IOP Publishing: Jepang

[13] Hidayat, Samsu, dan Agus Sigit Pramono. 2012. Kajian Pengaruh Arah Serat Komposit Pada Sayap HSFTB V2 Berdasarkan Gaya Aerodinamika. ITS Surabaya.

[14] Munasir. 2011. Studi Pengaruh Orientasi Serat Fiber Glass Searah dan Dua Arah Single Layer terhadap Kekuatan Tarik Bahan Komposit Polypropylene. Jurnal Penelitian Fisika dan Aplikasinya. Universitas Negeri Surabaya. 